Dra. Célia BELIM

Universidade de Lisboa. Portugal. celiabelim@gmail.com. https://orcid.org/0000-0001-9927-8018

\title{
Sofia LAGIDO
}

Universidade de Lisboa. Portugal. Sofia L. https://orcid.org/0000-0002-1333-8153

\section{Géneros e formatos televisivos da comunicação em saúde na televisão: O talk show Diga Doutor}

\section{Genres and formats of health communication in television: the talk show Diga Doutor}

\author{
Datas | Recepção: 29/05/2021 - Revisão: 29/05/2021 - Em edição: 10/06/2021 - Publicação final: 01/07/2021
}

\section{Resumo}

O artigo foca-se na caracterização do talk show sobre saúde Diga Doutor, na sua qualidade de género e de formato televisivo. A moldura teórica são os estudos televisivos e o método é o qualitativo, que incluia entrevistasemiestruturada e em profundidade à editora de conteúdos e ao médico-apresentador do programa, a análise da retórica a 12 episódios da última temporada do programa e o focus group composto por seis idosos, para assim se explorar respetivamente três componentes da comunicação: o emissor, a mensagem e o recetor. Os resultados indicam, sob a perspetiva do emissor, o compromisso com uma solução heterogénea e rica e a adoção de um estilo similar ao da consulta clínica, que permite, televisivamente, atingir o "maior número de pessoas possível", sem se ser "demasiado simplista". A análise à mensagem revela a diversidade temática e a presença de argumentos ligados ao ethos, pathos e logos, da retórica de Aristóteles. Os recetores realçam os contributos cognitivos, afetivos e comportamentais do programa, mostrando a articulação entre a identidade do programa e o gosto do público. O formato do programa manifesta-se nas sub-rotinas, como: o foco no "interesse público" e em "assuntos importantes" sobre saúde, a estrutura composicional, o segmento de comunicação interpessoal entre médico e telespetador, a presença in loco de especialistas e pacientes que partilham os seus testemunhos relacionados com a doença e/ou com a sua superação, os critérios de seleção do médico convidado e do paciente, a presença do "lado humano".

\section{Palavras-chave}

Género; formato; talk show; Diga Doutor; comunicação em saúde; estudos televisivos

\begin{abstract}
The article characterises the health talk show Diga doutor, in terms of its quality as television genre and format. The theoretical framework is television studies and the method is qualitative, including a semi-structured and in-depth interview with the content editor and the programme's doctor-presenter, a rhetorical analysis of twelve episodes of the programme's last season and a focus group comprising six elderly people, in order to explore three components of communication, respectively: the sender, the message and the recipient. The results indicate, from the perspective of the sender, the commitment to a heterogeneous and rich solution and the adoption of a style similar to that adopted in clinical consultations, which renders it possible, on television, to reach the "largest possible number of people", without being "over-simplistic". Analysis of the message reveals the thematic diversity and the presence of arguments related to the ethos, pathos and logos of Aristotle's rhetoric. The recipients highlight the programme's cognitive, affective and behavioural contributions, showing the link between the programme's identity and the public's preferences. The programme's format is manifested in the sub-routines, such as: focus on "public interest" and on "important issues" about health, the compositional structure, the interpersonal communication segment between doctors and viewers, the in loco presence of specialists and patients who share their testimonies related to the disease and/or overcoming it, the selection criteria governing the invited doctor and the patient, and the presence of the "human side".
\end{abstract}

\section{Keywords}

Genre; format; talk show; Diga Doutor; health communication; television studies 


\section{Introdução}

A saúde é o bem mais precioso do ser humano, pois sem ela, ou com ela debilitada, o desempenho humano ressente-se negativamente. A relação entre a presença da saúde e o equilíbrio, bemestar e vitalidade humanos motiva a que a saúde seja uma prioridade na agenda dos indivíduos independentemente da sua caracterização sociodemográfica e identidade cultural e, consequentemente e por contágio, na agenda mediática.

Por outro lado, a televisão, por ser um meio-rei, popular e de massas e, assim, ter um alcance amplo, tocando um grande leque de indivíduos, pode ser uma solução vantajosa para comunicar a saúde. Saúde e televisão podem, assim, constituir um produto atrativo para consumidores de conteúdos informativos, esclarecedores e pedagógicos. No contexto televisivo e por aquilo que a experiência revela, o talk show é um género que, pelas suas especificidades e identidade, tem cumprido as exigências que a abordagem à saúde implica. As dinâmicas conversacionais que remetem para a naturalidade da interação, a presença de profissionais de saúde, como médicos, e de pacientes que reportam as suas experiências e colocam perguntas/dúvidas ilustrando problemas e superações, o formato que desconstrói mitos e que inaugura uma linguagem simples e, assim entendível, permitindo o acesso graças à compreensão generalizada e facilitando o uso pelos recetores de orientações e conselhos de saúde alavancam o potencial do talk show. The Dr. Oz Show, Dr. Phil e outros talk shows médicos têm já provado o seu êxito, há mais de uma década, no panorama televisivo norteamericano, Neste âmbito, pretende-se estudar esta problemática no contexto português, explorando, para uma análise mais rica e completa, o emissor (editora de conteúdos e médico-apresentador do programa), a mensagem (presente em 12 emissões do programa) e o recetor (idosos).

Os géneros (e.g. do discurso), segundo Bakhtin (1986), dotam-se de "significado especial" (1986: 5) e de "extrema heterogeneidade" (1986: 60), pois, ao longo dos séculos, acumulam formas de ver e interpretar aspetos particulares do mundo (1986: 5). Ligado ao género, o formato é uma sub-rotina para lidar com temas específicos (McQuail, 2003: 340). Entre os temas específicos, encontra-se a saúde, que toca a todos (Wallington, 2014:169) e, como refere Emerson (1860), é a "primeira riqueza". A forma de interpretar (género) e de lidar com o tema da saúde através de sub-rotinas (formato) que importa no presente artigo é a televisiva, concretamente a observada no contexto do programa Diga Doutor, da Rádio e Televisão de Portugal (RTP). Esta opção permite fundamentar o artigo nos estudos televisivos, procurando-se quebrar fronteiras entre as agendas académicas que se têm focado em trabalho especializado sobre o medium televisivo e o espaço de ver televisão nas vidas de espetadores não especialistas para quem o medium funciona em vários modos nas suas experiências quotidianas (Bignell, 2012: 4).

Atendendo a que a comunicação "mantém-nos saudáveis" (Belim y Vaz de Almeida, 2018; Floyd, 2011: 4), nos últimos anos têm-se registado avanços no uso inovador da comunicação para abordar problemas de saúde pública (e.g. Cline, 2003: 285; Maibach y Holtgrave, 1995: 219).

Burzyńska, Binkowska-Bury e Januszewicz (2015) elogiam a televisão como fonte de informação sobre saúde, que tem a capacidade de influenciar o nível de conhecimento dos telespetadores, permitindo a identificação de sintomas simples, e de prevenir comportamentos de risco (2015: 174). Na mesma perspetiva de Kickbusch (2001), a televisão é descrita por Nielsen-Bohlman, Panzer y Kindig (2004) como uma fonte de informações certas e oportunas sobre vários temas em saúde, pois partilha histórias para milhões de pessoas num formato acessível a todos os níveis sociais (2004: 218). Também Almeida e Sebastião (2018) referem que "os pacientes têm maior conhecimento do seu processo de doença, por exemplo através dos programas televisivos, que os educam para uma melhor saúde" (2018: 38). Tendo fontes mais ricas do que os restantes media (Stroobant, Dobbelaer y Raermaeckers, 2017), a televisão foi o meio menos afetado pela COVID-19 (Grupo Marktest, 2020) e o principal meio que informou uma grande parte da população (Alarcón y Galeote, 2020: 106).

A par deste elogio, a televisão é o meio mais consumido pelos portugueses, evidenciando-se que $99 \%$ dos inquiridos veem regularmente programas televisivos (Entidade Reguladora para a Comunicação Social-ERC, 2016: 6, 22).

Por outro lado, a saúde e a segurança social é o tema que mais preocupa os portugueses (44\%) com uma subida de 11 pontos percentuais face ao período homólogo do ano transato (European Commission, 2019: 24). Portugal fica assim como o terceiro país europeu que mais importância atribui ao tema (European Comission, 2020). Os cuidados mais acentuados com a saúde e nutrição motivam a longevidade, ao conduzirem a que as "gerações mais velhas rejeitem os estereótipos e optem por estilos de vida mais equilibrados que Ihes permitam ultrapassar os 100 anos com qualidade" (Marketeer, 2016).

O programa selecionado é o Diga Doutor, que regista uma audiência média de 3,3\%, 317 mil e 100 
telespetadores e 12,8\% de share (MediaMonitor/CAEM, 2018), emitido pelo canal de serviço público português - a RTP1 - e, assim, comprometido em ser "uma referência para a população" orientada por "padrões éticos e qualitativos elevados" (Contrato de concessão do serviço público de rádio e de televisão, 2015: 5). Com três temporadas, o programa inicia-se em fevereiro de 2016 e finda a julho de 2018. Escolhe-se um programa televisivo atendendo a que: a) os estudos académicos sobre a televisão têm mostrado pouco interesse em tratar um programa ou tipo de televisão em detrimento de outro, constituindo uma lacuna de investigação (Bignell, 2004: 2); b) mas falando as pessoas sobre televisão por ser o meio mais consumido, estes programas têm uma presença alta na agenda (2004: 2). Por outro lado, seleciona-se um talk show, por ser um fenómeno mediático amplamente influente (llie, 2006: 489) e continuar a ser uma das mais populares e impactantes formas de programa televisivo (Mittell, 2003: 36).

Adotando a perspetiva dos estudos televisivos comprometida em definir como o medium comunica (Bignell, 2012: 2) e, baseados na questão de Mittell (2004) o que faz um certo género ser distinto? (2004: 2) e na sua constatação de que são poucos os académicos que procuram responder a esta questão, formula-se a pergunta de partida - Como é que o o talk show sobre saúde Diga Doutor comunica considerando o seu género e formato? Utiliza-se o método qualitativo, que inclui a entrevista, a análise da retórica e o focus group. Cada uma das técnicas permite conhecer um elemento do processo da comunicação: respetivamente o emissor, a mensagem e o recetor.

\section{Enquadramento teórico}

Este ponto inclui uma reflexão e uma revisão de literatura sobre a presença da comunicação em saúde em géneros e formatos televisivos e sobre o talk show como género.

A televisão organiza os seus produtos em géneros e formatos para seu facilitismo prático e para indicar às audiências o que podem, através desta tipificação, esperar desses produtos. Contudo, estes não são rótulos muralhados, podendo ser híbridos e intertextuais. Aplicados à comunicação da saúde, os géneros e formatos televisivos perfilham características específicas. Os estudos sobre talk shows médicos têm-se focado, sobretudo, na avaliação da qualidade das recomendações de saúde prestadas, nos tipos de formato e identidade que o talk show médico pode oferecer e no impacto deste sobre os recetores. A literatura mostra estas tendências, que são detalhadas a seguir.

\subsection{A comunicação em saúde em géneros e formatos televisivos}

Adota-se, neste artigo, o termo comunicação em saúde, para se refenir à comunicação que usa mensagens para promover a saúde, informar e influenciar os comportamentos dos indivíduos através dos conteúdos transmitidos (e.g. Teixeira, 2004) pelos programas televisivos de saúde.

Os géneros podem ser assumidos como tipos relativamente estáveis de expressões linguísticas que são determinados pelas esferas específicas da comunicação e que se refletem no conteúdo temático, no estilo e na estrutura composicional (Bakhtin, 1986: 60). Sobre o género mediático, McQuail (2003) especifica que é um mecanismo prático que ajuda qualquer meio de massas [como a televisão] a produzir, de modo consistente e eficiente, e a relacionar a sua produção com as expectativas das suas audiências (2003: 336). O autor caracteriza-o enunciando quatro traços: a) identidade coletiva, que persiste no tempo e resiste à mudança e que, sobrevivendo, requer que seja conscientemente expressa, reforçada e transmitida, sendo mais ou menos reconhecida, de modo idêntico, pelos seus produtores e consumidores. A identidade coletiva estipula a noção e o sentido de "nós" (Keulman y Koos, 2014) em vez dos de "eu", dependendo de uma crença coletiva de que a definição do grupo é compartilhada por todos os que lhe pertencem (Hermann y Brewer, 2004: 8). A identidade coletiva é um conceito multidimensional que comporta pelo menos três dimensões atitudinais: cognitiva, avaliativa e afetiva (Kaina y Karolewski, 2009: 13); b) relação desta identidade com finalidades (e.g. informação, entretenimento), formato (e.g. duração, ritmo, estrutura, linguagem) e significado (referência à realidade); c) identidade estabelecida diacronicamente e de acordo com convenções comuns; e d) adoção de uma estrutura previsível e de uma sequência de ação, assente num fundo expectável de imagens e com um repertório de variantes de temas/assuntos básicos (2003: 336). Estas quatro características são atendidas na formulação dos objetivos específicos do presente estudo.

O género, no meio televisivo, é a primeira forma de classificar o vasto leque de opções textuais da televisão (Mittell, 2001: 3). O género televisivo é uma categoria construída socialmente que permite comparar programas televisivos, em termos de assunto, estrutura narrativa, caracterização, cenário, estética (Mirrlees y Kispal-Kovacs, 2012: 100). Os géneros televisivos não são "paredes semânticas fortificadas" (2012: 100): não existem isoladamente, mas em relação com outros textos televisivos, sendo difícil fazer distinções nítidas entre um género televisivo e outro. Os géneros televisivos são, assim, intertextuais (Mirrlees y Kispal-Kovacs, 2012: 100; Mittell, 2001: 6) no sentido em que comunicam significado ao público por via de referências a outros textos televisivos (Casey, Casey, Calvert, French 
y Lewis, 2002: 127-128).

Para melhor articular a comunicação em saúde e o género televisivo, explora-se o conteúdo, o estilo e a estrutura composicional (Bakhtin, 1986). Murray-Johnson e Witte (2003) identificam diversas variáveis de conteúdo: referem-se aos estímulos, realçando que captar a atenção do público, mobilizando-o a participar, e que atuar sobre as mensagens são a chave para o êxito (2003: 474). Os teóricos identificam também as variáveis motivacionais. A motivação é essencial no modo como uma mensagem é processada e conduz ou não à ação (2003: 477). As mensagens em saúde são utilizadas para consciencializar, para aumentar o conhecimento ou para mudar comportamentos (2003: 477). O medo, na comunicação de mensagens de saúde, deve ser orientado de forma a que os indivíduos se possam proteger ou evitar uma potencial ameaça (2003: 478). Sharf e Vanderford (2003) asseveram que, quando se constroem histórias pessoais de sofrimento, o indivíduo compreende uma situação que pensa, inicialmente, não ter explicação plausível (2003: 29).

Na área da saúde, o estilo e, assim, a retórica afiguram-se significativos na medida em que, através da interação com o paciente, o médico é capaz de o persuadir a agir, seja para usar a medicação de forma adequada, para alterar a dieta ou para deixar de fumar (Sharf, 1990: 217). Adicionalmente, o uso da retórica pode fazer com que se curem ou previnam doenças e se aumente a longevidade do indivíduo (Sharf, 1990: 218). A retórica visa persuadir (Aristóteles, séculolV a.C./2005: 95-96).

Na retórica de Aristóteles (século IV a.C./2005), são identificadas três "provas de persuasão": a) as derivadas do caráter moral do orador, construindo a impressão de que é digno de fé (ethos); b) as centradas na emoção que o discurso estimula no público (pathos) e c) as que se focam no que o discurso demonstra (logos) (2005: 96-97). Hartelius e Browning (2008) referem que o ethos liga-se à confiança $e$ credibilidade que a audiência confere ao orador/emissor (2005: 29). Green (2004) assevera que os argumentos ligados ao pathos se imbricam nas emoções suscitadas e podem provocar uma ação social poderosa (2004: 659). O logos refere-se à clareza e utilidade de um argumento, apresentado numa base racional e lógica (Holt y Macpherson, 2010: 26).

Ainda em relação ao logos, as figuras deestilo conseguem tornar os pensamentos do orador concretos, ajudando a comunicar com o público de maneira mais clara e eficaz (Corbett, 2004: 143). Ting (2018) diz que o uso de dados/evidências e exemplos são parte do discurso lógico e racional (2018: 238). As frases normalmente iniciadas com por exemplo ilustram a declaração do orador e podem funcionar como evidências específicas que sustentam uma afirmação mais geral, contribuindo para uma melhor argumentação (Petric, 2007: 243). Ademais, as mensagens persuasivas, compostas por argumentos bilaterais, ou seja, por argumentos a favor e contra uma posição, favorecem a sua aceitação pela audiência (Hunt y Smith, 1987: 12). Ao apresentar-se ambos os lados de uma questão, a audiência considera o discurso mais justo por parecer menos tendencioso (Hunt y Smith, 1987: 12).

O género pode ser descrito nas suas propriedades organizativas. A estrutura é "a coleção de elementos ou partes e o conjunto de relacionamentos que ligam as partes" (Monge y Eisenberg, 1987: 305). Os constituintes da estrutura são definidos funcionalmente como ações (Schiffrin, 1990: 6). Todo o evento comunicativo institucional exige uma estrutura de papéis que transparecem no discurso, reproduzindo este uma estrutura social (Van Dijk, 2006: 278).

\subsection{O talk show como género televisivo para comunicar a saúde}

O talk show é um género altamente discursivo (llie, 2006: 489). A noção de talk show levanta questões sobre as fronteiras entre falar e mostrar, combinando dois paradigmas tendencialmente conflituantes, nomeadamente os paradigmas retóricos associados à conversa interpessoal (período pré-moderno) e o espetáculo mediado pelos mass media (período moderno) (Munson, 1993).

O talk show faz parte de um género precedente mais amplo, o reality show (CENGAGE, 2019) - a dita telerrealidade, que se baseia numa base unificadora: a dependência de eventos reais (CENGAGE, 2019). Nesta, as pessoas do "mundo quotidiano" estão submersas para desempenhar o seu papel (Lewis, 2004) e os espetadores encontram prazer nesses momentos de "verdade" (Hill, 2005). O género reality show é adequado ao meio televisivo pela forma como manipula o tempo como garante da realidade e da intimidade social (Kavka y West, 2004: 136). Isto não quer dizer que o uso da temporalidade presentista no reality show torne a realidade um documentário de experiência autêntica (2004: 136).

A identidade da televisão ou de um programa televisivo centra-se no que o define ou caracteriza, circunscrevendo-se não só à sua essência como também conduzindo a expectativas e julgamentos sobre o que, por exemplo, o programa deve fazer (Bignell, 2019: 161). Para capturar as características distintas do talk show, é essencial explorar o ambiente sociocultural e os fatores contextuais que 0 geraram e que continuam a moldá-lo. Os fatores contextuais - atendidos nos objetivos específicos referem-se ao formato, configuração, prazo e objetivo da televisão; a apresentação do perfil pessoal 
do anfitrião, a agenda e orientação geral; as experiências, objetivos e relações dos participantes (llie, 2006: 489). Mittell (2003), por exemplo, explica que o talk show oferece um caso de estudo particularmente rico em associar identidade e gosto (2003: 37). Ao examinar talk shows, deve-se atender a que o gosto do público é formado por - e formador de - definições de identidade cultural e que as categorias de identidade se ligam a outras categorias culturais, como géneros (Mittell, 2003: 37). As hierarquias e avaliações de genéricos são, muitas vezes, vinculadas diretamente a eixos de diferenciação em termos de identidade cultural dos espetadores (Mittell, 2003: 36).

Os talk shows giram sobre o debate público usando parcialmente a conversa, convenções e estratégias discursivas institucionais, que envolvem confundir os limites entre dicotomias tradicionais, como público vs. privado, experiência coletiva vs. experiência pessoal, especialização vs. experiência (llie, 2006: 489).

Cinco critérios são usados para definir os formatos de talk show: 1. Discussão de tópicos: desde assuntos políticos contemporâneos a problemas sociais e morais; 2. Categorias dos participantes tendo em conta o seu estatuto social e popularidade (celebridades, especialistas, membros ordinários do público); 3. Horário de transmissão (manhã, durante o dia, noite); 4. Estruturas organizacionais e interacionais (convenções de interação entre anfitrião e convidados); e 5. Considerações éticas (llie, 2006: 490). Todos estes critérios foram considerados na análise.

No inquérito online conduzido por Mittell (2003) e que reuniu uma amostra de 240 alunos da Universidade de Wisconsin-Madison, muitos inquiridos distinguem entre dois formatos/tipos de talk show: os focados no "interesse público" e em "assuntos importantes", imprimindo valores educacionais e sociais aos conteúdos, e os que se concentram em situações chocantes e "falsas", promovendo o entretenimento (2003: 41).

O estudo, conduzido por Din, Shahid e Abrar (2021), baseia-se numa análise de conteúdo a 33 programas de cinco talk shows paquistaneses populares que cobrem questões sociais, económicas e religiosas relacionadas com a pandemia da COVID-19. Os autores tencionam mostrar o uso do "jornalismo construtivo" em talk shows para incutir pensamentos positivos entre os telespetadores, com a intenção última de superar o medo e a incerteza. Entre os cinco indicadores (introdução do talk show, relevância dos convidados, presença de diferentes perspetivas em discussão, contributo da pessoa-âncora e desfecho da discussão) usados para analisar a cobertura construtiva, notase a ausência de alguns nos talk shows paquistaneses estudados: a seleção do convidado, muitas vezes, não é feita com base no tópico do programa, sendo difícil produzir uma discussão equilibrada e racional; o "ingrediente" mais ausente é a abordagem orientada para a solução do problema. O padrão de talk show televisivo no Paquistão, geralmente, inclui um debate político e finda sem qualquer declaração conclusiva (Ali y Rahman, 2018). Também nos talk shows albaneses, Luku (2013) verifica a ausência do debate racional e da diversidade de pensamento (2013: 578). Adicionalmente, percebe-se a falta de público participante no debate público porque: a) os apresentadores encaram com ceticismo o envolvimento do público no programa, vindo esta lógica da tradição de pensar que são as elites que fazem a televisão e que os espetadores apenas assistem; b) na maioria dos órgãos de comunicação social, não há critérios de seleção quanto ao público sentado no estúdio, sendo a sua presença concebida como decoração do estúdio (2013: 578). Ainda se observa que a discussão nos talk shows albaneses é orientada por interesses económicos (2013: 578).

Entre os estudos acerca de programas televisivos sobre saúde, Korownyk e outros (2014) focam-se na análise das recomendações de saúde dos talk shows The Dr. Oz e The Doctors, com o objetivo de determinar a sua qualidade. Os autores conduziram um estudo observacional prospetivo, procedendo à seleção aleatória de 40 emissões de cada um dos programas em análise desde o início de 2013, e avaliaram todas as recomendações feitas, concluindo que o benefício destas não foi específico na maioria das vezes (2014:24). No entanto, no geral, as recomendações tinham algum nível de evidência publicada para apoiá-las (2014: 25): no The Doctors, a maioria das recomendações foi apoiada em evidências credíveis, enquanto que, no The Dr. Oz Show, apenas se verificou credibilidade em $33 \%$ das recomendações (2014: 25).

Outros estudos procuram perceber a influência de programas de saúde sobre os indivíduos ao nível da saúde. Uma das dimensões dos efeitos dos media é a cognitiva, afetiva e comportamental, que marca uma distinção entre a aquisição de conhecimento sobre uma ação e o desempenho da ação (Perse y Lambe, 2016: 18). Podem-se identificar cinco efeitos dos media sobre o indivíduo: 1. comportamentais, que ocorrem quando o telespetador realiza alguma ação transmitida pelos media; 2. atitudinais, quando os media moldam as opiniões, crenças e valores dos telespetadores; 3 . cognitivos, quando os media mudam o pensamento ou o conhecimento do indivíduo; 4. emocionais, que se referem à produção de sentimentos no telespetador; e 5. fisiológicos, referindo-se a reações corporais físicas, provocadas pelos media, sendo a excitação um dos exemplos (Nabi y Oliver, 2009).

Intentando averiguar o impacto do programa The Dr. Oz Show nos comportamentos relacionados 
com a saúde e examinar se a informação sobre saúde influencia as atitudes e comportamentos dos participantes sobre saúde, Crouch, Dickes, Davis e Zarandy (2016) conduziram um teste aleatório em grupo e entre grupos, com 50 profissionais de saúde voluntários de uma unidade de saúde familiar. Concluem que, após a visualização do The Dr. Oz Show, não se verificou diferença estatisticamente significativa nos hábitos alimentares, de exercício físico ou na necessidade de participar num grupo de perda de peso (2016: 376). Contudo, os autores admitem que o estudo se encontra limitado, pois os participantes eram profissionais de saúde, maioritariamente caucasianos e com alto nível de escolaridade (2016: 376). Também Park, Chang e Kwon (2003) apuram que a taxa de prática de comportamentos de saúde desejáveis, depois de assistir a programas de saúde em televisão, foi baixa. Crouch e outros (2016), assim como Park, Chang e Kwon (2003), verificam que o motivo de a generalidade dos espetadores assistir a programas de saúde na televisão era entretenimento ou diversão (2003: 376).

Explorando a função utilitária de programas televisivos sobre saúde, Paek, Choi e Hove (2017) conduzem a análise a programas deste tipo na Coreia do Sul. Aplicando questionários a 1020 adultos sul coreanos, concluem que os adultos mais velhos, as mulheres e "as pessoas mais conscientes" e mais confiantes neste tipo de programa tendem mais a reconhecer a utilidade dos programas, a visualizá-los e a recomendá-los (2017: 541).

Jeong e Lee (2018) analisam os talk shows médicos The Dr. Oz Show e The Doctors. Ao inquirirem mulheres sul coreanas telespetadoras de talk shows médicos, conclvem que não existe uma relação entre a frequência da exposição a informações de programas televisivos médicos e a aceitação incondicional dessas informações (2018: 976). Observam, adicionalmente, que os sujeitos que não entendem a informação, por ser confusa, nem sempre a acatam (2018: 977).

Park, Chang e Kwon (2003) estudaram a influência de programas televisivos recreativos, relacionados com a saúde, sobre o comportamento saudável. Recolhendo informações de 200 respondentes, descobrem que a taxa de comportamento de saúde desejável, depois de assistir a estes programas, foi baixa, mas que estes programas, atendendo a que a inclusão de especialistas em saúde foi o fator mais influente, seriam benéficos na condição de aliarem fatores de recreação com evidências científicas.

Também Dutta (2007), através de dois estudos - o primeiro recorrendo ao inquérito e o segundo a um estudo piloto e questionário -, pretendeu perceber o contributo da televisão na aprendizagem sobre saúde. O autor avaliou as fontes de informação televisiva, questionando os participantes sobre a sua aprendizagem em saúde através dos programas de televisão, e examinou a diferença de conhecimento sobre "a relação entre exercício e humor" entre os que se consideravam orientados para a saúde e os que tinham baixa orientação em saúde. Detetou, a partir do primeiro estudo, que os indivíduos que relataram aprender alguma coisa sobre doença e a sua prevenção a partir de programas médicos e de saúde são mais orientados para estas informações temáticas, em comparaçãocom os que referiram não aprender algo (Dutta, 2007).

Ainda Hoffman, Shensa, Wessel, Hoffman e Primack (2017), através do seu estudo baseado numa revisão de literatura, pretenderam aferir a capacidade de os programas de televisão médicos afetarem os resultados de saúde pública. Observam que $78 \%$ dos estudos, que analisaram, revelam uma associação positiva entre a visualização e o comportamento de saúde sob avaliação. Perceberam, também, que, em $50 \%$ dos estudos analisados sobre o conhecimento, os participantes aprenderam informações de saúde corretas a partir da exposição.

Por fim, o estudo de Edgerly, Gotlieb e Vraga (2016) mostra que os telespetadores de um talk show noticioso se envolvem mais com o conteúdo quando o estilo do talk show é compatível com as suas necessidades psicológicas, notando-se que "aquele programa, realmente, falou comigo!" (2016: 1950). Conduzindo um projeto experimental com 326 indivíduos a residir nos Estados Unidos da América, os investigadores testaram duas instâncias de compatibilidade: uma que fomenta o debate crítico e acolhe espetadores com necessidades cognitivas e outra promotora de comentários humorísticos e anfitriã de espetadores com necessidades de humor. Quando a compatibilidade ocorreu, os espetadores perceberam o talk show noticioso como mais relevante, o que aumentou a atividade cognitiva e comportamental em relação ao conteúdo ao qual se expuseram.

\section{Método}

A pergunta de partida - Como é que o talk show sobre saúde Diga Doutor pode ser caracterizado em termos de género e formato? conduz a investigação, definindo-se como objetivos: 1) conhecer o género e o formato do programa a partir das escolhas comunicacionais dos emissores, concretamente da responsável pela pesquisa e conteúdos e do médico-apresentador; 2) compreender como está construído o género e o formato a partir da mensagem e 3) discutir o género e o formato do programa considerando os efeitos cognitivos, afetivos e comportamentais assumidos pelo telespetador. Os 
objetivos permitem conhecer a identidade (McQuail, 2003: 336) e as quatro características de género mediático propostas por McQuail (2003), entre elas a de formato (e.g. duração, ritmo, estrutura, linguagem); a associação entre identidade e gosto (Mittell, 2003: 37); o conteúdo-estilo-estrutura composicional da proposta de Bakhtin (1986); os fatores contextuais que geraram e moldaram o talk show (llie, 2006: 489), os critérios para definir o formato de talk show (llie, 2006: 490) e o formato/tipo de talk show (Mittell, 2003: 41).

As técnicas qualitativas usadas são: a entrevista, a análise da retórica e o focus group, respondendo cada uma a um objetivo. Para cumprir o primeiro objetivo realizou-se a entrevista semiestruturada e em profundidade à editora de conteúdos, Andreia Nogueira, a 20 de março de 2019 e ao médicoapresentador, João Ramos, a 14 de março de 2019.

Para concretizar o segundo objetivo, opta-se pela análise da retórica (Tabela 1).

Tabela 1: Matriz para a análise da retórica, com subcategorias do ethos, pathos e logos

\begin{tabular}{|c|c|c|}
\hline Ethos & Pathos & Logos \\
\hline $\begin{array}{l}\text { Capacidade: o emissor mostra- } \\
\text { se como alguém que é capaz } \\
\text { de ajudar e ser útil para os } \\
\text { doentes (Borges y Júnior, 2008: } \\
\text { 10) }\end{array}$ & $\begin{array}{l}\text { Calma: argumentos que } \\
\text { provocam nos espetadores } \\
\text { "liberdade da dor", ou seja, } \\
\text { fazem com que o telespetador } \\
\text { não tenha receios (Aristóteles, } \\
\text { century IV B.C./2004: } 76 \text { ) }\end{array}$ & $\begin{array}{l}\text { Verdade e lógica: } \\
\text { argumentos verdadeiros } \\
\text { (Belim y Filipe, 2019: 148) }\end{array}$ \\
\hline $\begin{array}{l}\text { Conhecimento: o emissor } \\
\text { mostra saber dados concretos } \\
\text { que inspiram confiança e } \\
\text { credibilidade (Belim y Filipe, } \\
\text { 2019: 157) }\end{array}$ & $\begin{array}{l}\text { Medo/Receio: argumentos } \\
\text { usados que fazem com que o } \\
\text { espetador sinta que o referido } \\
\text { o pode afetar ou causar-lhe } \\
\text { sofrimento (Aristóteles, century } \\
\text { IV B.C./2004: } 81 \text { ) }\end{array}$ & $\begin{array}{l}\text { Referência a dados } \\
\text { estatísticos (Ting, 2018: 238) }\end{array}$ \\
\hline \multirow[t]{4}{*}{$\begin{array}{l}\text { Identidade: o emissor descreve } \\
\text { o que faz de modo a inspirar } \\
\text { credibilidade para poder falar } \\
\text { sobre o tema em questão } \\
\text { (Borges y Júnior, 2008: 10) }\end{array}$} & $\begin{array}{l}\text { Estímulo à reflexão: argumentos } \\
\text { que levam a que o telespetador } \\
\text { pense no seu comportamento e } \\
\text { a agir em conformidade (Belim } \\
\text { y Filipe, 2019: 160) }\end{array}$ & $\begin{array}{l}\text { Provas: estudos científicos } \\
\text { e/ou testemunhas (Borges y } \\
\text { Júnior, 2008: 10) }\end{array}$ \\
\hline & $\begin{array}{l}\text { Empatia: o espetador poderá } \\
\text { colocar-se na posição } \\
\text { da pessoa (testemunha } \\
\text { geralmente) e sente o que } \\
\text { sentiria a pessoa nos argumentos } \\
\text { utilizados, caso estivesse na } \\
\text { mesma situação (Belim y Filipe, } \\
\text { 2019: 160) }\end{array}$ & $\begin{array}{l}\text { Figuras de estilo } \\
\text { (Corbett, 2004): } \\
\text { metáfora, comparação, } \\
\text { personificação, antítese e } \\
\text { anáfora }\end{array}$ \\
\hline & $\begin{array}{l}\text { Admiração: o espetador sente } \\
\text { consideração pela pessoa } \\
\text { que fala, por ser uma pessoa } \\
\text { importante ou porque possui } \\
\text { algo de bom, que é altamente } \\
\text { apreciado (Aristóteles, century } \\
\text { IV B.C./2004: 87) }\end{array}$ & $\begin{array}{l}\text { Uso de exemplificações: } \\
\text { frases que ilustram a } \\
\text { declaração do orador } \\
\text { (Petric, 2007: 243) }\end{array}$ \\
\hline & & $\begin{array}{l}\text { Argumentos unilaterais } \\
\text { e bilaterais: apresentam } \\
\text { argumentos a favor e contra } \\
\text { uma posição defendida } \\
\text { (Hunt y Smith, 1987: 12) }\end{array}$ \\
\hline
\end{tabular}


O corpus compõe-se de 12 episódios da última temporada do programa - janeiro a julho de 2018 (Tabela 2) do programa televisivo Diga Doutor, que contou com um total de 23 episódios. Escolhe-se a última de três temporadas, seguindo o critério da atualidade e o princípio da recentidade. Já o número de episódios selecionados resulta de um processo amostral probabilístico aleatório, garantindo um mínimo de $50 \%$ de episódios da temporada. A opção por uma amostra não fragiliza o estudo pois, como salienta Cortès (1999), a definição de conteúdos de um programa tem sempre subjacente uma "filosofia da programação", que consolida a ideia do projeto, ou uma linha editorial, que marca os critérios a seguir. Por outro lado, e sendo o programa em análise exibido na RTP, televisão com a concessão de serviço público, obedece às regras de programação compósita, em que a estratégia de programação conduz à produção de uma grelha que se caracteriza por uma grande diversidade temática, mas sem descurar a coerência entre os programas para o perfil de um dado público-alvo, ao contrário do que acontece com as regras de programação federativo que visam essencialmente a concentração do grande público (Mehl, 1992: 162).

Tabela 2: Composição do corpus

\begin{tabular}{|c|c|c|}
\hline Episódio & Temática & Intervenientes convidados \\
\hline 2 & Linfomas & $\begin{array}{l}\text { - Daniela Alves - especialista em hematologia } \\
\text { - Joelma - testemunha: doente com linfoma } \\
\text { - Maria da Silva - hematologista do IPO de Lisboa }\end{array}$ \\
\hline 3 & Gripe e vacinação & $\begin{array}{l}\text { - Graça Freitas - Diretora-geral da Saúde } \\
\text { - Lisa Joanes - Homeopata }\end{array}$ \\
\hline 6 & Trânsito intestinal & $\begin{array}{l}\text { - Jaime Midões - gastroenterologista } \\
\text { - Jorge Fonseca - gastroenterologista } \\
\text { - Alexandra Vasconcelos - especialista em medicina } \\
\text { natural e integrativa }\end{array}$ \\
\hline 7 & $\begin{array}{l}\text { Apneia obstrutiva } \\
\text { do sono }\end{array}$ & $\begin{array}{l}\text { - Carla Amaro - otorrinolaringologista } \\
\text { - David Barbosa - testemunha com apneia do sono } \\
\text { - Rita Talhas - nutricionista }\end{array}$ \\
\hline 8 & Pedra nos rins & $\begin{array}{l}\text { - Paulo Vale - urologista } \\
\text { - Luís Batista - testemunha } \\
\text { - Maria de Vasconcelos - nutricionista }\end{array}$ \\
\hline 9 & Cancro do pulmão & $\begin{array}{l}\text { - Ricardo da Luz - oncologista } \\
\text { - Javier Gallego - cirurgião cardiotorácico }\end{array}$ \\
\hline 10 & Fígado gordo & $\begin{array}{l}\text { - Leopoldo Matos - gastroenterologista } \\
\text { - Pedro Bastos - investigador na área da nutrição }\end{array}$ \\
\hline 11 & $\begin{array}{l}\text { Envelhecimento } \\
\text { ativo }\end{array}$ & $\begin{array}{l}\text { - Clotilde Ferreira - testemunha } \\
\text { - Georgina do Valle - pediatra } \\
\text { - Andreia Silva - Direção-Geral da Saúde }\end{array}$ \\
\hline 14 & $\begin{array}{l}\text { Doenças } \\
\text { autoimunes }\end{array}$ & $\begin{array}{l}\text { - Luís Campos - medicina interna } \\
\text { - Tânia Vilhabol - testemunha com lúpus } \\
\text { - Ilda Pallet - testemunha com síndrome de sjogren } \\
\text { - Ângela Ramos - com síndrome de anticorpo } \\
\text { antifosfolípido }\end{array}$ \\
\hline 16 & $\begin{array}{l}\text { Saúde íntima da } \\
\text { mulher }\end{array}$ & - Fernando Cirurgião - ginecologista \\
\hline 19 & $\begin{array}{l}\text { Défice de atenção } \\
\text { com ou sem } \\
\text { hiperatividade }\end{array}$ & $\begin{array}{l}\text { - Fernando Santos - pedopsiquiatra } \\
\text { - Filipe Silva - pediatra }\end{array}$ \\
\hline
\end{tabular}

Fonte: elaboração própria.

A análise foi aplicada episódio a episódio e verificada por um segundo investigador. No fim de toda a análise e para efeitos de otimizar a qualidade desta, comparam-se as análises feitas episódio a episódio e ambos os investigadores avaliaram (e afinaram) a coerência em toda a análise conduzida. 
O terceiro objetivo foi concretizado através de um focus group com seis - quatro mulheres e dois homens - idosos (65 e mais anos) (INE, 2002) por serum dos grupos etários que mais assistiu ao programa Diga Doutor - 25,6\% (MediaMonitor/CAEM, 2018) -, indo ao encontro da ideia de que ver televisão é "uma importante atividade de lazer para os mais velhos" (van der Goot, Beentjes y van Selm, 2012: 147). Atendeu-se, também, a outras características sociodemográficas deste grupo populacional de telespetadores, como o status social, região (predominância do norte) e género (predominância de mulheres), e à assiduidade do participante como telespetador deste tipo de programa no último ano - critério usado no estudo de Jeong e Lee (2018) - e que permite conhecer e comparar os efeitos não imediatos e imediatos do talk show.

Atendendo a este perfil e por conveniência, os idosos incluídos no focus group provêm do Centro Social e Cultural de Vila Praia de Âncora, Viana do Castelo. Para a concretização do focus group, feito a 18 de março de 2019, selecionou-se aleatoriamente um episódio do programa Diga Doutor, que foi exibido antes da discussão. Este episódio foi o 26, da temporada 1, sobre quiroprática e acupuntura.

Após a visualização do episódio, o moderador foi avançando cada uma das questões do guião, previamente concebido, e incentivou, com respeito pelos princípios éticos (e.g. respeito pela diversidade de opiniões, não incentivo de pré-respostas), a participação dos idosos.

\section{Resultados}

\subsection{Género e formato do programa Diga Doutor a partir do emissor}

Nota-se o compromisso com uma solução heterogénea a partir da definição dos objetivos, que o programa intenta cumprir, enunciados pelos entrevistados: a) desmitificar, acalmando os telespetadores; b) alertar, motivando a que os telespetadores "procurem os serviços de saúde, mas de forma mais acertada ou mais assertiva" e c) garantir a receção correta de informação, para que possam saber quando é que devem recorrer ao seu médico ou à urgência (Ramos).

Em termos das escolhas, que se verteram no formato, o Diga Doutor forma-se a partir do interesse por programas de serviço público do antigo diretor da RTP1, Daniel Deusdado, que escolhe o médico João Ramos pela sua "imagem simpática" e porque "a mensagem dele chegava às pessoas" (Nogueira). Na escolha do médico-apresentador, o critério principal foi tratar-se de alguém que "soubesse falar em televisão", i.e., que conseguisse explicar "para o senso comum" e o médico João Ramos tinha essa capacidade (Nogueira). Além disto, o feedback, recebido dos telespetadores, indicava que "gostavam muito do João" (Nogueira). Ramos considera que a sua credibilidade é garantida pela sua profissão, que é respeitada pela população. Atesta que o seu trabalho é muito valorizado, não só pela população no geral, como pela comunidade médica, que "diz que eu estou a fazer um bom trabalho".

Os critérios usados para definir a agenda temática/conteúdo do programa são: a) as efemérides, i.e., "os dias comemorativos" - e.g. no mês do cancro da mama, falava-se sobre a doença; b) a possibilidade de fazer boas reportagens sobre um tema - e.g. "chegou-nos a hipótese de acompanhar algumas cirurgias, sendo este um critério para a agenda: temos esta cirurgia para fazer reportagem, vamos colocar este tema neste mês no programa"; c) a existência de cinco temas de interesse geral: "osteoporose, diabetes, colesterol, alergias e cancro" e d) a sazonalidade do tema: "há determinados temas que são para falar no verão e outros que são para falar no inverno" (Nogueira).

Sobre o estilo de linguagem utilizado, Nogueira e Ramos afirmam que não se adotou qualquer fórmula e que a linguagem do médico era a das suas consultas. Contudo, havia certos cuidados, como: a) não utilizar "muitos termos técnicos" e, quando utilizados, descodificá-los transformando as palavras mais complexas da medicina num "português mais corrente" (Ramos). Nogueira explica o desafio linguístico: "fazer um paralelo entre a linguagem técnica e a linguagem que as pessoas usam no dia a dia"; b) usar uma linguagem esclarecedora e percetível de imediato (Nogueira) e c) o médico estar permanentemente atualizado sobre doenças, normas, "sobre tudo" (Ramos). A comunicação em saúde, na televisão, é um desafio, pois exige que se fale de forma clara e transparente, para chegar ao "maior número de pessoas possível", sem se ser "demasiado simplista" (Ramos). Outro desafio apontado pelo médico é não induzir o telespetador a um comportamento de risco por não ter percebido ou por o médico não se ter explicado bem (Ramos).

A inspiração para a construção do programa proveio do The Dr. Oz, da norte-americana Sony Entertainment Television, e do Bem-Estar, da brasileira Globo, almejando "abordar temas de saúde de forma mais criativa" (Nogueira). Mas "todo o processo de criação do programa" partiu, em grande parte, de João Ramos (Nogueira). Em termos de estrutura composicional, Ramos seleciona dois convidados: um especialista sobre o tema tratado no programa e outro que aborde de "forma mais prática" "um subtema do tema", como fisioterapeutas, terapeutas da fala ou psicoterapeutas (Nogueira). Um dos segmentos do programa é a utilização de uma comunicação interpessoal entre 
médico e telespetador, através da resposta pelo primeiro às perguntas feitas diretamente pelo interlocutor, zelando pelo compromisso de esclarecer dúvidas (Nogueira).

Ramos e Nogueira afirmam que a escolha dos médicos convidados depende especialmente: a) do prévio contacto e do "elo de ligação" de João Ramos com eles, proporcionando um "à vontade natural", o que garantia que "resultasse melhor"; b) falar para a televisão; c) dom da palavra do médico convidado. Os médicos convidados eram preparados no dia anterior e era-lhes explicado que o desafio residia em desmitificar questões de uma forma simples, sempre com o cuidado da "clareza da linguagem" e, aquando do uso de um termo mais técnico, João Ramos descodificá-lo-ia. As perguntas feitas aos médicos eram em direto, sem que houvesse o conhecimento a priori daquelas (Nogueira).

O critério de seleção dos pacientes era serem doentes dos médicos convidados, para que estes "pudessem comentar" com domínio, por já os conhecerem e ao seu histórico clínico (Nogueira). Ramos assevera que a presença destes "casos" contribui para o êxito do programa Diga Doutor, ao trazer "um lado mais humano" e que "o espetador sente-se mais ligado ao doente e revê-se como doente e na linguagem".

Ramos assevera que as pessoas aprendem e que estão habituadas a receber informação sobre saúde através da televisão. Dá o exemplo concreto de pacientes que, em consulta, partilharam que viram o programa, aprenderam e até explicaram questões a familiares. No entanto, e, apesar destes efeitos cognitivos, refere que "a população ainda tem muito pouco conhecimento sobre coisas muito simples" ou, como diz Nogueira, "temos muito analfabetismo em áreas de saúde". Mas, para Ramos, este programa contribui para o aumento da literacia em saúde, na medida em que esclarece questões não a uma única pessoa num consultório, mas sim "a cerca de meio milhão de pessoas" e isto conduzirá a que "daqui a dez anos tenham muito mais cultura e saibam muito mais das doenças e da prevenção do que agora". Nogueira aponta dois fatores que comprovam que o programa aumentou a literacia em saúde nos telespetadores: a) a confiança que os telespetadores depositam no médico, ou seja, "as pessoas ficam muito mais esclarecidas quando ouvem alguém em quem confiam" e b) o esclarecimento sobre temas de saúde durante quarenta minutos, que permite elucidar as pessoas sobre um só tema sob vários ângulos.

\subsection{Género e formato do Diga Doutor a partir da análise à mensagem}

Os assuntos (conteúdo) são variados dentro do chapéu temático da saúde: havendo, dentro do corpus, dois assuntos de índole feminina e três sobre o cancro.

Em relação aos intervenientes convidados, percebe-se que estão ligados ao assunto na agenda do dia do programa, e.g. no episódio seis o assunto é "trânsito intestinal" e os intervenientes convidados são gastroenterologistas. Para além disto, são sempre mais do que um, com exceção do episódio dezasseis. Também, em cinco dos doze episódios que compõem o corpus, estão presentes testemunhas com a patologia apresentada na emissão do dia.

Sobre o estilo e no que toca ao ethos e às suas subcategorias, a "capacidade" está presente em quase todos os episódios com exceção dos episódios seis e dez. Exemplos: "nós hoje já conseguimos fazer os doentes sobreviverem mais tempo" (médico Ricardo da Luz, ep. 9); "eu explico, garanto que as pessoas percebem o que é que se passa e depois avançamos em conjunto" (médico Fernando Santos, ep. 19).

O "conhecimento" aparece referenciado em todos os episódios do programa. Exemplos: "10 a 15\% dos doentes têm algum tipo de diarreia quando tomam antibióticos" (médico Jorge Fonseca, ep. 6); "é uma doença que atinge principalmente mulheres entre os 18 e os 50 anos" (médico Luís Campos, ep. 14).

Por último, em relação à "identidade" referem-se os exemplos: "eu sou uma médica de linfomas" (Maria da Silva, ep. 2); "eu sou médico de família e quem contacta muitas vezes com a população somos nós" (João Ramos, ep. 3).

Em relação ao pathos, a subcategoria "calma" aparece em todos os episódios com exceção do onze. Exemplos: "nem todas as lesões evolvem no mau sentido" (João Ramos, ep. 21); "por uma mulher ter lúpus não quer dizer que o filho tenha" (médico Luís Campos, ep. 14).

O "medo/receio" aparece em todos os episódios, com exceção do onze. Exemplos: "as pessoas estão muito automedicadas e há muitos medicamentos que produzem alteração do funcionamento intestinal e obstipação" (médico Jaime Midões, ep. 6); "as pessoas começam a viver o tempo suficiente para poderem ter um cancro do pulmão" (médico Ricardo da Luz, ep. 9). 
São exemplos da presença da subcategoria "estímulo à reflexão": "o ideal é as pessoas vacinaremse durante o outono para que quando o vírus estiver em maior circulação, no inverno, já estarem protegidas" (Graça Freitas, ep. 3); "as pessoas com doenças autoimunes têm que ter uma alimentação equilibrada e evitar esforços muito violentos" (médico Luís Campos, ep. 14).

A "empatia" não aparece representada em cinco episódios, sendo maioritariamente gerada pelos casos, ou seja, pelas pessoas que vão testemunhar. Exemplos: "quero fazer tudo o que fazia antigamente e não posso: estou limitada porque sinto dores" (Tânia, ep. 14) "desde o primeiro caso, tem sido um sofrimento muito grande" (Luís, ep. 8).

A subcategoria "admiração" é a que surge menos representada, aparecendo apenas num episódio. Exemplos: "tem 92 anos e ainda dá aulas de ioga, é autónoma e ainda conduz" (João Ramos, ep. 11); "trabalho muitas vezes até às onze/meia-noite e começo de manhã" (médica Georgina do Valle, ep. 11).

No âmbito do logos e em relação à subcategoria "verdade e lógica/inferências" recolheram-se como exemplos: "o alimento em si próprio não é obstipante" (médico Jaime Midões, ep. 6); "o tabaco tem milhares de substâncias tóxicas que fazem mal a tudo e mais alguma coisa" (médico Ricardo da Luz, ep. 9).

O uso de dados estatísticos coincidirá, em parte, com a subcategoria "conhecimento" do ethos, acima mencionado. Exemplos: "uma em cada três mulheres vai ter uma vaginose" (João Ramos, ep. 16): "em 90/95\% das cirurgias, temos sempre o equipamento de vídeo de alta definição no bloco operatório" (Javier Gallego, ep. 9). Nos episódios sete e dois, não há qualquer referência.

A grande maioria dos episódios recorre a "provas" com exceção dos episódios três e dezasseis. Em metade dos episódios do corpus - nos episódios 2, 7, 8, 11, 14, 21 -, as provas utilizadas são as testemunhas, sendo que os episódios 11 e 14 recorrem a mais do que uma testemunha.

As figuras de estilo são usadas em todos os episódios, identificando-se: a comparação, a personificação, a metáfora, a anáfora e a antítese e, ainda, o recurso a ditados populares. Exemplos: a) comparação: "os fungos são como os cogumelos e dão-se muito bem com o calor" (médico Fernando Cirurgião, ep. 16); b) personificação: "aqueles chás inocentes de infusão" (médico Paulo Vale, ep. 8); c) metáfora: "a imunidade é o nosso exército, mas se os terroristas estiverem bem escondidos não os encontramos" (médico Ricardo da Luz, ep. 9); d) anáfora: "há anos em que aparece mais cedo, há anos em que aparece mais tarde, há anos em que afeta mais pessoas, outros menos pessoas, há anos em que é mais grave, outros menos grave" (médica Graça Freitas, ep. 3); e) antítese: "vivemos inundados numa sociedade de informação e desinformação ao mesmo tempo" (João Ramos, ep. 10) e f) ditados populares: "é, de facto, melhor prevenir do que remediar" (Graça Freitas, ep. 3).

As "exemplificações" são utilizadas em todos os episódios, como: "por exemplo, quando eu digo que o linfoma está na medula as pessoas dizem "ai já está nos ossos" - fazem a analogia com a metastização óssea" (médica Daniela Alves, ep. 2); "eu tenho um caso em que ela tem 38 anos, já foi tratada, mas, desde os 26, que não ia ao médico" (médica Teresa Fraga, ep. 21).

Em todos os episódios, há o recurso a argumentos bilaterais, visto que, em cada tema, são referidos aspetos positivos e negativos relacionados com aquele. Exemplos: episódio 2 - "os linfomas indolentes não precisam de ser tratados logo, podem esperar algum tempo e isso é vantajoso para o doente" (médica Maria da Silva) e "nos linfomas indolentes, por mais que nos esforcemos, não conseguimos atingir a cura" (médica Daniela Alves); episódio 16 - "os bifidus, ao melhorarem a flora intestinal, acabam por ter impacto positivo na flora vaginal" (médico Fernando Cirurgião) e "o antibiótico, ao matar, mata tudo e mata essas bactérias boas, o que faz com que cresçam as outras" (médico Fernando Cirurgião).

\subsection{Género e formato do Diga Doutor a partir do telespetador}

No que se refere aos efeitos não imediatos, foram vários os participantes que afirmaram aprender com este programa, confirmando os efeitos cognitivos: Alice refere "eu via o programa do Doutor João Ramos porque assim ficava elucidada, porque havia coisas que ele falava que já se tinham passado comigo e assim eu aprendia", Maria diz que "achava interessante porque [o médico] explicava muito bem as coisas" e Henriqueta e Carlos concordam que, apesar de nos dias que correm se aprender pouco com a televisão, estes programas "são muito educativos, educam velhos e novos". Miguel diz, também, que "ao ver alguns episódios uma pessoa percebe sempre que cuidados deve ter, ou novas maneiras de nos tratarmos, mesmo por nós, em casa, coisas que devemos mudar".

Alguns participantes deram exemplos para provar como aprenderam através do Diga Doutor. Carlos 
elucida: "aconselharam que, se estivéssemos sentados durante muito tempo, devíamos mexer os pés e as pernas e as mãos, e eu tenho feito isso". Alice conta que "uma vez no programa disseram que não se devia fazer todos os anos análises e eu tinha essa mania. Até comentava, muitas vezes, que os médicos não queriam passar análises, mas que o deviam fazer, para perceber como é que as pessoas estavam. Mas afinal eles [emissores do programa] disseram que isso não era recomendável."

Explorando os efeitos cognitivos imediatos, Miguel relata que "não sabia o que era a quiroprática, nem como se fazia. E não sabia que os problemas da coluna influenciavam outras coisas, como a bexiga, como disse o convidado". Henriqueta menciona que "o que eu percebi é que há uma ligação entre a coluna e o sistema nervoso e é, a partir daí, que estes médicos especialistas tratam a pessoa, porque é o sistema nervoso que controla tudo. E também que através da quiroprática, como o médico disse e exemplificou, pode-se ajustar vértebras, que era o tal ajustamento que ele fez à convidada". Carlos refere que "também não sabia o que era a quiroprática e, ao exemplificarem, percebeu-se muito bem e parece-me que deve ter resultados". Contrariamente, Conceição realça: "não consegui perceber muito bem o que era isso da quiroprática, sei que é das costas, mas não entendi o que se faz muito bem, vi lá o médico a analisar a senhora, mas não entendi o que é que resolve a mais que os outros tratamentos". No entanto diz que "não sabia que, através da acupuntura, se podia tratar coisas psicológicas e stress, pensava que era para só para as dores".

Na dimensão afetiva, os participantes referem entre os efeitos não imediatos: a) receio: "sinto receio porque vê-se tantas coisas, tantas doenças, que uma pessoa fica sempre de pé atrás. Penso que ainda posso ter mais coisas do que aquelas que já tenho" (Conceição); b) agrado em aprender: "eu sinto que aprendo, gosto sempre de ver, porque as coisas são muito bem explicadas" (Maria), "é sempre importante ver estas coisas e aprender" (Miguel) e c) curiosidade: "sinto muita curiosidade, gosto de estar sempre a aprender coisas novas e já me levou a experimentar" (Alice).

Entre os efeitos imediatos, os participantes referem que sentiram a) curiosidade e interesse por aprender: "senti interesse em conhecer coisas que não sabia, como era o caso da quiroprática" (Alice), "senti alguma curiosidade de experimentar os tratamentos, por causa das dores de costas" (Carlos), "eu também gostei: muito interessante perceber que há tratamentos, que não a medicina convencional, que são tão bons" (Henriqueta) e b) indiferença: "eu não senti nada, não sei, acho que não tenho muito interesse no assunto" (Maria), "eu também não senti nada, são coisas que existem. Fiquei a saber mais. Mas não me aquece nem me arrefece" (Conceição).

Sobre efeitos comportamentais há divergências quer nos efeitos não imediatos quer nos imediatos. Em termos de efeitos não imediatos, Miguel diz que não sente necessidade de ir a uma consulta depois de ver um programa, porque "já fiquei esclarecido, a não ser que o médico, na televisão, diga que quem sinta aquilo deve ir a uma consulta. Mas mesmo assim eu não vou. Para quê?!". Contrariamente, Alice conta: "foi por ver um programa destes que fui ao médico. É um método de ver doenças através dos olhos e foi lá a especialista e fiquei tão curiosa que fui experimentar". Acerca dos efeitos imediatos, Carlos e Henriqueta ponderam o tratamento e até marcar uma consulta: "se houvesse aqui este tratamento ia: gostava de experimentar para ver se estas dores aliviam" (Carlos). Já Alice e Miguel dizem que não vão alterar o seu comportamento, porque "até agora não sinto dores de costas" (Alice) e "não me despertou muito interesse" (Miguel).

\section{Discussão e conclusões}

Focado na saúde, qualquer programa ou comunicação mediático atrai potencialmente interesse e atenção do recetor - independentemente da sua idade, embora os idosos, a par com indivíduos com baixa escolaridade e baixos rendimentos, por se depararem com mais problemas e complicações de saúde e maior risco de adoecer (Observatório Português dos Sistemas de Saúde-OPSS, 2016: 129), são os que poderão reconhecer maior utilidade na exposição a estes programas temáticos - porque a saúde toca a todos (Wallington, 2014: 169) e, como refere Emerson (1860), é a "primeira riqueza". Schopenhaver, também, captou perfeitamente uma necessidade humana profundamente sentida ao escrever que "saúde não é tudo, mas sem saúde tudo é nada". Este pressuposto está de acordo com a argumentação de Stiglitz, Sen e Fitoussi (2009) de que a saúde é, provavelmente, o aspeto mais fundamental da qualidade de vida, uma vez que, sem saúde, todos os outros componentes da qualidade de vida têm pouco valor (2009: 156-157). Discutindo essa causalidade, existe uma vasta literatura revelando as consequências nefastas para o indivíduo derivadas de choques negativos à sua saúde.

O Diga Doutor é um programa com uma solução heterogénea e rica, em virtude das funções que cumpre: a vigilância social à saúde, a partilha de factos, esclarecimentos e perspetivas diversas sobre saúde, desmitificando e acalmando espetadores, a tentativa de ajudar na tomada de decisões quotidianas ligadas à saúde, alertando e motivando à procura acertada dos serviços de saúde, e a garantia da receção correta de informação. Diferentemente, no estudo de Crouch e outros (2016) e de Park, Chang e Kwon (2003), a componente 
lúdica é a dominante na perspetiva dos telespetadores, que declaram assistir a programas televisivos de saúde motivados pela necessidade de entretenimento ou diversão. Conforme a classificação de Mittell (2003: 41), nota-se, assim, em Diga Doutor, o formato de talk show focado no "interesse público" e em "assuntos importantes", em contraste com os que fomentam o entretenimento.

O programa oferece informação atualizada e, simultaneamente, tenta convencer para a prática de comportamentos saudáveis e preventivos, almejando novidade ao "abordar temas de saúde de forma mais criativa". Portanto, assume os preceitos da comunicação em saúde que se pauta por promover, informar e influenciar sobre a saúde, conforme a definição de Teixeira (2004). As combinações, que são feitas no programa, vertem na sua identidade.

A identidade hibrida do programa, envolvendo "pessoas, práticas e plataformas" (Carlson, 2015: 2), revela-se 1. na especificidade das pessoas: médico que exerce um papel de polivalência no contexto do programa (autor de "todo o processo de criação do programa", apresentador, condutor, fonte de informação, decisor de conteúdos, decisor sobre os convidados presentes), médicos, pacientes; e 2. nas sub-rotinas que compõem o formato, como a duração (média de 40 minutos), a periodicidade da emissão (semanal: sábados no período matutino), o estilo de linguagem (acessível), a estrutura composicional, o segmento de comunicação interpessoal entre médico e telespetador, a presença in loco de especialistas e de pacientes, os critérios de seleção do médico convidado e do paciente. $\bigcirc$ "Iado humano" - como, por exemplo, a referência a casos concretos, com pacientes em estúdio que dão voz às suas histórias, sendo uma prática no programa - "ajuda a personalizar e a conectar" (Bate, 2004: 68).

Duas características de Diga Doutor contradizem as observações de Din e outros (2021): a escolha de especialistas e pacientes é feita com base na adequação temática do programa, ao invés do que acontece nos talk shows paquistaneses analisados, em que a seleção do convidado não se motiva, tendencialmente, pelo tópico sob tratamento; o Diga Doutor mostra terapias e tratamentos para resolver problemas, orientando-se por uma lógica de soluções, já os talk shows paquistaneses não seguem esta linha orientativa. Traçando uma comparação com os talk shows albaneses (Luku, 2013), o Diga Doutor premeia o debate racional e a pluralidade de perspetivas ao convidar diversos especialistas e pacientes, não acontecendo o mesmo com os talk shows emitidos na Albânia; e os pacientes/público têm um contributo participativo ao reportar a sua história de saúde e ao colocarem questões, já na Albânia impera o ceticismo quanto ao envolvimento do público, cumprindo a lógica tradicionalista de que são as elites que fazem a televisão e exercendo o público uma função de presença meramente cénica ou cenográfica.

Tal como no estudo de Park, Chang e Kwon (2003), percebe-se, em termos de estilo/retórica, que a presença do médico (ethos) influencia a confiança dos telespetadores no programa. Os participantes do focus group avaliam o médico como "digno de fé" (Aristóteles, século IV a.C./2005: 96-97), referindo que "nota-se que ele sabe", e a informação como "séria". Tal pode influenciar a sua aprendizagem através do programa, pois a credibilidade do emissor conduz à persuasão do recetor (Burgoon, Birk y Pfau, 1990) e a aceitação da mensagem é, grosso modo, influenciada por julgamentos acerca da competência do comunicador - a sua habilidade para fazer afirmações válidas - e acerca da sua confiabilidade - a sua intenção para expressar apenas afirmações que considera confiáveis (Lind y O'Barr, 1979).

O estilo de linguagem simples, claro ou percetível, desconstrutor de terminologia técnica, é o adotado no programa Diga Doutor. Pois, na intenção de garantir o acesso, a compreensão e o uso de conteúdos sobre saúde por parte do recetor, a linguagem clara é uma resposta lógica e flexível (Stableford y Mettger, 2007: 75). Este estilo de linguagem faz parte da solução para os principais problemas de saúde, não se tratando de negligenciar a necessidade de precisão (Stableford y Mettger, 2007): trata-se de comunicar com transparência e significado, com uma linguagem criativa, vibrante e emocionalmente ressonante, em que o processo de conceção de conteúdos requer conhecimento e habilidades, uma compreensão correta do público-alvo e o uso de uma abordagem baseada em factos (Stableford y Mettger, 2007: 76-81). Também televisivamente, as analogias ou histórias da vida real poderão ser úteis (Mayeaux, Murphy, Arnold, Davis, Jackson y Sentell, 1996), porque os pacientes entendem mais debilmente as comunicações de saúde com mais frequência do que os médicos podem pensar (Brega, Freedman, Leblanc, Barnard, Mabachi, Cifuentes, Albright, Weiss, Brach y West, 2015: 16; Howard, Jacobson y Kripalani, 2013).

De forma a persuadir o telespetador a reunir conhecimento ou alterar comportamentos, o logos foi utilizado em todos os programas tanto pelo médico-apresentador como pelos convidados. O uso da "verdade e lógica/inferências" pode ser influente, conforme o estudo de Park, Chang e Kwon (2003). A presença de testemunhas (provas) é relevante para o êxito deste programa, como referido pelo médico João Ramos, porque a construção de histórias pessoais de sofrimento ajuda o indivíduo a compreender determinadas situações (Sharf y Vanderford, 2003: 29). Estas histórias almejam influenciar o comportamento e, noutros casos, acrescentar dramatismo, com a intenção de promover comportamentos saudáveis (Moyer-Gusé, 2008: 409). As figuras de estilo ajudam a concretizar e a 
clarificar o discurso do orador (Corbett, 2004: 143). O uso de exemplificações permite uma melhor ilustração da declaração do orador (Petric, 2007: 243). Por fim, no que diz respeito aos argumentos bilaterais, estes mostram os dois lados da questão (positivo e negativo), o que favorece a aceitação da mensagem e dos argumentos (Hunt y Smith, 1987: 12).

Verificou-se que o programa Diga Doutor contribui para a literacia em saúde da população, tal como é referido por Andreia Nogueira e João Ramos. Apurou-se, portanto, que o Diga Doutor, tem efeitos cognitivos sobre o telespetador. E, tal como no estudo de Hoffman e outros (2017), observou-se que os telespetadores adquiriram mais conhecimento sobre o assunto de saúde tratado no programa, imediatamente após a sua visualização (2017: 118). Isto explica-se porque os telespetadores retêm as mensagens apresentadas na televisão e tendem a emular os comportamentos que observaram e que consideram como desejáveis (Moyer-Gusé, 2008: 408).

A nível afetivo (pathos), os sentimentos referidos pelos participantes do focus group ao assistirem ao programa são: a) receio; b) agrado em aprender; c) curiosidade e d) indiferença. O receio pode equiparar-se ao medo, e é fundamental na transmissão das mensagens em saúde, de maneira a que os indivíduos se possam precaver em relação às doenças (Murray-Johnson y Witte, 2003: 478).

O agrado em aprender pode remeter para a corrente funcionalista (funções dos media) e a teoria dos usos e gratificações, que explica a forma como os indivíduos usam os media - neste estudo as mensagens do talk show Diga Doutor -, na satisfação das suas necessidades (Katz, Blumler y Gurevitch, 1973). Neste caso, o programa satisfaz as necessidades cognitivas, identificadas por Katz, Blumler y Gurevitch (1973), que estão relacionadas com a consolidação de informação e de conhecimento.

Em relação à curiosidade, pode-se inferir que esta motiva a que o recetor passe para o plano comportamental. Alice é o exemplo dessa transição da exposição à mensagem para a ação. São vários os participantes que afirmam terem alterado comportamentos e recorrido ao médico após a visualização de um episódio.

Na análise da retórica realizada, são identificados sentimentos, como a calma. Coincidentemente, João Ramos, também, identifica como objetivo do Diga Doutor acalmar os telespetadores. Segundo Aristóteles (century IV B.C./2004), a "calma" faz com que o espetador experiencie "ausência da dor" (century IV B.C./2004: 76).

Outros sentimentos encontrados na mensagem concebida no programa Diga Doutor são o medo/ receio, o estímulo à reflexão, a empatia e a admiração. O apelo por medo tem vindo a revelarse eficaz para influenciar positivamente atitudes, intenções e comportamentos, registando-se muito poucas circunstâncias em que não é eficaz e não havendo circunstâncias identificadas sob as quais ocorram resultados indesejáveis (Tannenbaum, Hepler, Zimmerman, Jacobs, Wilson y Albarracín, 2015). As mensagens que estimulam a reflexão podem ser úteis, por convidarem o recetor a pensar sobre o conteúdo que descodifica, podendo este conduzi-lo à ação positiva e, portanto, a favor do comportamento saudável e/ou preventivo. Percebe-se que o programa Diga Doutor veicula mensagens que despertam a empatia, que é a capacidade de perceber o quadro interno de referência do outro com precisão e com os componentes e significados emocionais dele, como se fosse ele, mas sem nunca perder a condição "como se" (Rogers, 1959: 210-211). Esta capacidade permite que o recetor compreenda o outro e se coloque nos seus sapatos. A presença, no programa Diga Doutor, de cidadãos comuns, que partilham as suas experiências de saúde, ajuda a estimular a capacidade/sentimento de empatia e a dar um rosto e uma voz a problemas de saúde que podem ser vividos por quem os vê e ouve e também a soluções e comportamentos que podem inspirar e motivar a ação. Por sua vez, a admiração por outros - pouco estudada academicamente, apesar do seu contributo e das potenciais implicações (Haidt y Seder) - incentiva as pessoas a aprender habilidades valiosas (Immordino-Yang y Sylvan, 2010) e facilita a aprendizagem social (Haidt y Seder, 2009). Onu, Kessler e Smith (2016) propõem o modelo conceptual da admiração. Os autores explicam que a admiração é provocada por pessoas de competência superior e que se associa à reflexão sobre a competência do alvo e a uma tendência à imitação, que facilita a aprendizagem social (2016: 9-11).

A identidade do programa (Bignell, 2019: 161) e o gosto do telespetador, a que se refere Mittell (2003), encontram-se no programa, permitindo otimizar a aceitação da comunicação em saúde pelos telespetadores que o programa pretende transmitir. É neste encontro que poderá estar a identidade coletiva, se se usar o termo de McQuail (2003: 336).

O género e o formato de um programa imprimem-lhe identidade, embora se perceba que há margem e liberdade para a criatividade, inovação e experimentação de soluções por parte dos produtores e emissores. Pode-se também dizer o contrário: um programa pode desafiar e ampliar a definição de género e de formato. A apropriação do tema de saúde por um talk show - neste 
caso, pelo Diga Doutor - mostra-se uma solução gratificante para os telespetadores que recebem compensações cognitivas (e.g. aprendizagem, conhecimento), afetivas (e.g. sentimentos que inspiram comportamentos saudáveis) e comportamentais (adoção de decisões e práticas de saúde recomendáveis e de alternativas para resolução de problemas de saúde e/ou para otimização da qualidade de vida). Estas compensações podem ocorrer graças à compatibilidade entre o estilo e identidade do talk show e as necessidades psicológicas do telespetador, conforme os resultados apurados por Edgerly, Gotlieb e Vraga (2016).

Em termos de contributos teóricos, procura-se, com este estudo, a) quebrar fronteiras entre as agendas académicas focadas em trabalho especializado sobre a televisão como medium e o espaço de ver televisão, trazendo a perspetiva prática e utilitarista do telespetador, que foi um desafio lançado por Bignell (2012: 4), e b) responder à lacuna que a literatura apresenta de se focar pouco em tratar um programa (Bignell (2012: 2) e c) à pergunta de Mittell (2004): o que faz um certo género televisivo neste caso, o talk show - ser distinto? (2004: 2).

Os contributos práticos residem na riqueza de resultados sobre o talk show e sobre a utilidade deste em prol da saúde, aliando três perspetivas: a do emissor, a da mensagem e a do recetor. Conhecendo estas três perspetivas, sobretudo a do recetor, na prática os produtores de conteúdos podem adotar e/ ou afinar sub-rotinas que permitam uma melhor articulação entre a identidade do programa televisivo e o gosto e "compatibilidade" dos telespetadores.

Sobre propostas futuras de investigação, sugere-se que se estudem mais programas televisivos que tratem de saúde, de modo a perceber como a comunicação em saúde se configura em géneros e formatos.

\section{Contribuição específica de cada autor}

\section{Contribuições}

Conceção e desenho do trabalho

Pesquisa documental

Coleta de dados

Análise e interpretação crítica dos dados

Revisão e aprovação das versões

\section{Nome e apelido dos autores}

Célia Belim, Sofia Lagido

Célia Belim, Sofia Lagido

Célia Belim, Sofia Lagido

Célia Belim, Sofia Lagido

Célia Belim, Sofia Lagido

\section{Referências bibliográficas}

[1] Alarcón, E. V. \& Galeote, L. C. (2020). COVID-19 media coverage on Spanish public TV. Tripodos, 47(2), 103-125. https://doi.org/gfwh

[2] Ali, F. \& Rahman, B. H. (2018). Political bias in talk shows: A case of MQM in local bodies election 2015. Journal of Media Studies, 33(1), 1-23. https://bit.ly/3i3ZqRv

[3] Almeida, C. y Sebastião, S. (2018). A perceção dos profissionais de saúde sobre fontes de informação e sua influência na relação terapêutica. Observatorio (OBS*), 12 (4), 26-43. https://doi.org/gfwj

[4] Aristóteles. (século IV a.C./2005). Retórica. Lisboa: Imprensa Nacional-Casa da Moeda.

[5] Aristóteles. (century IV B.C./2004). Rhetoric. n.I.: Courier Corporation.

[6] Bakhtin, M. (1986). Speech genres and other late essays. Austin: University of Texas Press.

[7] Bate, P. (2004). The role of stories and storytelling in organisational change efforts: A field study of an emerging "community of practice" within the UK National Health Service. In B. Hurwitz; T. Greenhalgh \& V. Skultans (Eds.), Narrative research in health and illness (pp. 325-348). Oxford, England: Blackwell.

[8] Belim, C. \& Filipe, P. (2019). «Mirror, mirror, on the wall, who's the most/less European of them all?»). Refugees and leader communication patterns. Problemi dell'informazione, 145-174.

[9] Belim, C. \& Vaz de Almeida, C. (2018). Healthy thanks to communication: A model of communication competences to optimize health literacy - Assertiveness, clear language, and positivity. In V. E. Papalois \& M. Theodospoulou (Eds.), Optimizing health literacy for improved clinical practices (pp. 124-152). Hershey, PA, USA: IGI Global. 
[10] Bignell, J. (2012). An introduction to television studies. London, England; New York, USA: Routledge.

[11] Bignell, J. (2019). Performing the identity of the medium: Adaptation and television historiography. Adaptation, 12(2), 149-164. https://doi.org/gfwk

[12] Borges, J. y Júnior, V. (2008). A construção do sentido e a retórica das empresas na web. Cadernos EBAPE.BR, 6(5), 1-21. https://doi.org/gfwm

[13] Brega, A. G.; Freedman, M. A. G.; LeBlanc, W. G.; Barnard, J.; Mabachi, N. M.; Cifuentes, M.; Albright, K.; Weiss, B. D.; Brach, C. \& West, D. R. (2015). Using the health literacy universal precautions toolkit to improve the quality of patient materials. Journal of Health Communication, 20(2), 69-76. https://doi.org/gfwn

[14] Burgoon, J. K.; Birk, T. \& Pfau, M. (1990). Nonverbal behaviors, persuasion and credibility. Human Communication Research, 17(1), 140-169. https://doi.org/ffhn2c

[15] Burzyńska, J.; Binkowska-Bury, M. \& Januszewicz, P. (2015). Television as a source of information on health and illness: Review of benefits and problems. Progress in Health Sciences, 5(2), 174-184.

[16] Carlson, M. (2015). Introduction: The many boundaries of journalism. In M. Carlson y S. C. Lewis (Eds.), Boundaries of journalism (pp. 1-18). NY, USA: Routledge.

[17] Casey, B.; Casey, N.; Calvert, B.; French, L. \& Lewis, J. (2002). Television Studies: The Key Concepts. New York, USA: Routledge.

[18] CENGAGE. (2019). Reality television. https://bit.ly/3i97JeP

[19] Cline, R. (2003). Everyday interpersonal communication and health. In T. Thompson; A. Dorsey; K. Miller y R. Parrott (Eds.), Handbook of health Communication (pp. 285-313). NJ, USA: Lawrence Erlbaum Associates.

[20] Corbett, E. (2004). Classical rhetoric. In J. Rivkin \& M. Ryan (Eds.), Literary theory, an anthology (pp. 142-161). Maiden: Blackwell.

[21] Cortès, J. (1999). La estrategia de la seducción: La programación en la neotelevision. Madrid, España: Eunsa.

[22] Crouch, E.; Dickes, L.; Davis, A. \& Zarandy, J. (2016). The effects of Dr. Oz on health behaviors and attitudes. American Journal of Health Education, 47(6), 373-378. https://doi.org/gfwq

[23] Din, A. M.; Shahid, A. \& Muhammad, A. (2021). Use of constructive approach in talk shows: A case of post corona raised social, economic and religious issues in Pakistan. Journal of Media Studies, 36(1), 1-22. https://bit.ly/2RbxlOw

[24] Dutta, M. (2007). Health information processing from television: The role of health orientation. Health Communication, 21 (1), 1-9. https://doi.org/dtp7qv

[25] Edgerly, S.; Gotlieb, M. \& Vraga, E. (2016). "That show really spoke to me!": The effects of compatible psychological needs and talk show host style on audience activity. International Journal of Communication, 10, 1950-1970. https://bit.ly/34u5E51

[26] Emerson, R. W. (1860). The conduct of life. Boston, USA: Ticknor and Fields.

[27] ERC. (2016). As novas dinâmicas do consumo audiovisual em Portugal. Lisboa, Portugal: ERC.

[28] European Comission. (2019). Public opinion in the European Union. Belgium: EC.

[29] Floyd, K. (2011). Interpersonal communication: The whole story. New York, USA: McGraw-Hill.

[30] Green, S. (2004). A rhetorical theory of diffusion. Academy of Management Review, 29(4), 653669. https://doi.org/cjnpd7

[31] Grupo Marktest. (27/03/2020). Covid 19 nos media. https://bit.ly/3yNaokn

[32] Haidt, J. \& Seder, P. (2009). Admiration and awe. In D. Sander \& K. Scherer (Eds.), Oxford companion to affective science (pp. 4-5). New York, NY, USA: Oxford University Press. 
[33] Hartelius, E. \& Browning, L. (2008). The application of rhetorical theory in managerial research. Management Communication Quarterly, 22(1), 13-39. https://doi.org/fxdr27

[34] Hermann, R. \& Brewer, M. B. (2004). Identities and institutions: Becoming European in the EU. In R. K. Hermann; T. Risse \& M. B. Brewer (Eds.), Transnational identities. becoming European in the EU (pp. 1-22). Lanham, MD: Rowman \& Littlefield.

[35] Hill, A. (2005). Reality TV: Audiences and popular factual television. London, UK; New York, NY: Routledge.

[36] Hoffman, B.; Shensa, A.; Wessel, C.; Hoffman, R. y Primack, B. (2017). Exposure to fictional medical television and health: A systematic review. Health Education Research, 32(2), 107-123. https://doi.org/f9wb74

[37] Holt, R. \& Macpherson, A. (2010). Sensemaking, rhetoric and the socially competent entrepreneur. International Small Business Journal, 28(1), 20-42. https://doi.org/cxmmn3

[38] Howard, T.; Jacobson, K. L. \& Kripalani, S. (2013). Doctor talk: Physicians' use of clear verbal communication. Journal of Health Communication, 18(8), 991-1001. https://doi.org/ghpht9

[39] Hunt, J. \& Smith, M. (1987). The persuasive impact of two-sided selling appeals for an unknown brand name. Journal of the Academy of Marketing Science, 15(1), 11-18. https://doi.org/ck5vcw

[40] llie, C. (2006). Talk Shows. In K. Brown (Editor-in-Chief), Encyclopedia of Language \& Linguistics (vol. 12, pp. 489-494). Oxford, England: Elsevier.

[41] Immordino-Yang, M. H. \& Sylvan, L. (2010). Admiration for virtue: Neuroscientific perspectives on a motivating emotion. Contemporary Educational Psychology, 35(2), 110-115.

[42] INE (2002). O envelhecimento em Portugal: Situação demográfica e socio- económica recente das pessoas idosas. Lisboa, Portugal: INE.

[43] Jeong, J. \& Lee, S. (2018). The influence of information appraisals and information behaviors on the acceptance of health information: A study of television medical talk shows in South Korea. Health Communication, 33(8), 972-979. https://doi.org/gfwr

[44] Kaina, V. \& Karolewski, I. P. (2009). EU governance and European identity. Living Reviews in European Governance, 4(2), 1-41. https://doi.org/gfws

[45] Katz, E.; Blumler, J. \& Gurevitch, M. (1973). Uses and gratifications research. Public Opinion Quarterly, 37(4), 509-523. https://doi.org/bw3sm7

[46] Kavka, M. \& West, A. (2004). Temporalities of the real: Conceptualizing time in reality TV. In S. Holmes \& D. Jermyn (Eds.), Understanding reality television (pp.136-153). Oxon, UK: Routledge.

[47] Keulman, K. \& Koos, K. A. (2014). European identity: Its feasibility and desirability. Lanham, Maryland: Lexington Books.

[48] Kickbusch, I. (2001). Health literacy: Addressing the health and education divide. Health Promotion International, 16(3), 289-297. https://doi.org/fmkcg3

[49] Korownyk, C., Kolber, M. R., McCormack, J., Lam, V., Overbo, K., Cotton, C., Finley, C., Turgeon, R.D., Garrison, S., Lindblad, A.J., Banh, H. L., Campbell-Scherer, D., Vandermeer, B., \& Michael-Allane, B. (2014). Televised medical talk shows - what they recommend and the evidence to support their recommendations: A prospective observational study. British Medical Journal, 349(7346), 24-25. https://doi.org/gb3sn8

[50] Lewis, J. (2004). The meaning of real life. In S. Murray \& L. Ouellette (Eds.), Reality TV: Remaking television culture (pp. 288-302). New York, NY: New York University Press.

[51] Lind, E. A. \& O'Barr, W. M. (1979). The social significance of speech in the courtroom. In H. Giles \& R. St Clair (Eds.), Language and social psychology (pp. 66-87). Oxford, England: Blackwell.

[52] Luku, E. (2013). A look at the public sphere in talk show programs in Albania. Mediterranean Journal of Social Sciences, 4(10), 574-579. https://doi.org/gf73

[53] Maduro, M.; Rodrigues, M.; Reis, G.; Silva, N. y Tomé, C. (06/03/2015). Contrato de concessão do serviço público de rádio e de televisão. https://bit.ly/3uye99N 
[54] Maibach, E. \& Holtgrave, D. (1995). Advances in public health communication. Annual Reviews Public Health, 16, 219-236. https://doi.org/bgahdr

[55] Marketeer. (2016). 10 tendências globais sobre consumidores. Disponible en https://bit.ly/3pnDTok

[56] Mayeaux Jr, E. J.; Murphy, P. W.; Arnold, C.; Davis, T. C.; Jackson, R. H. \& Sentell, T. (1996). Improving patient education for patients with low literacy skills. American Family Physician, 53(1), 205-211.

[57] McQuail, D. (2003). Teoria da Comunicação de massas. Lisboa, Portugal: FCG.

[58] MediaMonitor/CAEM. (2018). Evolução dados de audiência 2018: Diga Doutor e Consultório. Lisboa, Portugal: MMW/YUMI.

[59] Mehl, D. (1992). La fenêtre et le miroir: La télévision et ses programmes. Paris, France: Payot.

[60] Mirrlees, T. \& Kispal-Kovacs, J. (2012). Television reader: Critical perspective in Canadian and US television studies. Oxford, England: Oxford University Press.

[61] Mittell, J. (2001). A cultural approach to television genre theory. Cinema Journal, 40(3), 3-24. https://bit.ly/3yNJTLy

[62] Mittell, J. (2003). Audiences talking genre: Television talk shows and cultural hierarchies. Journal of Popular Film and Television, 31 (1), 36-46. https://doi.org/d853sp

[63] Mittell, J. (2004). Genre and television: From cop shows to cartoons in American culture. New York, USA; London, England: Routledge.

[64] Monge, P. R. \& Eisenberg, E. M. (1987). Emergent communication networks. In F. M. Jablin; L. L. Putnam; K. H. Roberts \& L. W. Porter (Eds.), Handbook of organizational communication: An interdisciplinary perspective (pp. 304-342). Newbury Park, California, USA: Sage.

[65] Moyer-Gusé, E. (2008). Toward a theory of entertainment persuasion: explaining the persuasive effects of entertainment-education messages. Communication Theory, 18, 407-425. https://doi.org/ffk8vj

[66] Munson, W. (1993). All talk: the talk show in media culture. Philadelphia, USA: Temple University Press.

[67] Murray-Johnson, L. \& Witte, K. (2003). Looking toward the future: Health message design strategies. In T. Thompson; A. Dorsey; K. Miller \& R. Parrott (Eds.), Handbook of health communication (pp. 473495). NJ, USA: Lawrence Erlbaum Associates.

[68] Nabi, R. \& Oliver, M. (2009). The SAGE handbook of media processes and effects. California, USA: Sage.

[69] Nielsen-Bohlman, L.; Panzer, A. \& Kindig, D. (2004). Health literacy: A prescription to end confusion. Washington, DC, USA: The National Academies Press.

[70] Observatório Português dos Sistemas de Saúde-OPSS. (2016). Saúde: Procuram-se novos caminhos - Relatório de Primavera 2016. Portugal: OPSS. https://bit.ly/3fx0U50

[71] Onu, D.; Kessler, T. \& Smith, J. R. (2016). Admiration: A Conceptual Review. Emotion Review, 8(3), 218-230. https://doi.org/gfwv

[72] Paek, H.; Choi, M. \& Hove, T. (2017). Intention to view health TV programs in South Korea: An application of the comprehensive model of information seeking. Journalism \& Mass Communication Quarterly, 94(2), 526-551. https://doi.org/gbj7z3

[73] Park, S. H.; Chang, H. J. \& Kwon, Y. D. (2003). Study on the influence of health information from TV - amusement programs on practice of health behavior. Korean Journal of Health Education and Promotion, 20(1), 187-202.

[74] Perse, E. y Lambe, J. (2016). Media effects and society. NY, USA: Routledge.

[75] Petric, B. (2007). Rhetorical functions of citations in high-and low-rated master's theses. Journal of English for Academic Purposes 6(3), 238-253.

[76] Rogers, C. R. (1959). A theory of therapy, personality and interpersonal relationships as developed in the client-centered framework. In S. Koch (Ed.), Psychology: a study of a science (pp. 184-256). New York, USA: MCGraw-Hill. 
[77] Schiffrin, D. (1990). The principle of intersubjectivity in communication and conversation. Semiótica, 80(1/2), 121-151.

[78] Sharf, B. (1990). Physician-patient communication as interpersonal rhetoric: A narrative approach. Health Communication, 2(4), 217-231. https://doi.org/cvmk7v

[79] Sharf, B. \& Vanderford, M. (2003). Illness narratives and the social construction of health. In T. Thompson; A. Dorsey; K. Miller \& R. Parrott (Eds.), Handbook of health communication (pp. 9-34). NJ, USA: Lawrence Erlbaum Associates.

[80] Stableford, S. \& Mettger, W. (2007). Plain language: A strategic response to the health literacy challenge. Journal of Public Health Policy, 28(1), 71-93. https://doi.org/ddv8cw

[81] Stiglitz, J. E.; Sen, A. \& Fitoussi, J. P. (2009). Report by the Commission on the Measurement of Economic Performance and Social Progress. https://bit.ly/3c6LWRb

[82] Stroobant, J.; Dobbelaer, R. D. \& Raeymaeckers, K. (2017). Tracing the sources. Journalism Practice, 12(3), 344-361. https://doi.org/gfww

[83] Tannenbaum, M. B.; Hepler, J.; Zimmerman, R. S.; Saul, L.; Jacobs, S.; Wilson, K. \& Albarracín, D. (2015). Appealing to fear: A meta-analysis of fear appeal effectiveness and theories. Psychological Bulletin, 141 (6), 1178-1204. https://doi.org/f7wvhw

[84] Teixeira, J. (2004). Comunicação em saúde: Relação técnicos de saúde - utentes. Scielo Portugal, $22(3), 615-620$.

[85] Ting, S. (2018). Ethos, logos and pathos in university students' informal requests. Journal of Language Studies, 18(1), (234-251). https://doi.org/gfwx

[86] Van der Goot, M.; Beentjes, J. W. J. \& Van Selm, M. (2011). Meanings of television in older adults' lives: an analysis of change and continuity in television viewing. Ageing and Society, 32 (01), 147-168. https://doi.org/d54wwp

[87] Van Dijk, T. (2006). Ideologia. Barcelona, España: Gedisa.

[88] Wallington, S. (2014). Health disparities research and practice: The role of language and health communication. In H. Hamilton \& W. Chou (Eds.), The Routledge handbook of language and health communication (pp. 168-183). Oxon: Routledge. 